\title{
MIXED GLIAL CHORISTOMA OF TONGUE AND GASTRO-INTESTINAL HETEROTOPIA OF ORAL CAVITY IN A NEWBORN WITH CLEFT PALATE
}

\author{
S. Pratap Rao¹, B. Jyothsna², Sana Salim Khan³ ${ }^{3}$ M. Sravanthi, C. N. Prasad ${ }^{5}$
}

\section{HOW TO CITE THIS ARTICLE:}

S. Pratap Rao, B. Jyothsna, Sana Salim Khan, M. Sravanthi, C. N. Prasad. "Mixed Glial Choristoma of Tongue and Gastro-Intestinal Heterotopia of Oral Cavity in a Newborn with Cleft Palate". Journal of Evolution of Medical and Dental Sciences 2014; Vol. 3, Issue 21, May 26; Page: 5748-5752, D0I: 10.14260/jemds/2014/2659

ABSTRACT: Mixed choristoma of oral cavity are uncommon lesions that show a variety of clinical presentations. Mixed choristoma with cleft palate is a very rare developmental malformation. We report an unusual case of glial choristoma from anterior two third and lateral border of tongue and intestinal heterotopia from soft tissues of neck occupying left sub mandibular region. Heterotopic brain tissue of the tongue is considered to be one of the very rare choristomatous lesions in the new born. The term choristoma means normal tissue in an abnormal location. The etiology and pathogenesis remain debatable. Glial choristoma is a developmental malformation of heterotopic central nervous tissue with limited growth potential. Oral glial choristoma affecting neonates do not show any intracranial communication. Gastro intestinal choristoma is a well described entity in gastrointestinal tract.

KEYWORDS: cleft palate, choristoma, glial, heterotopia, intestinal, tongue.

INTRODUCTION: Choristoma refers to presence of normal tissue found in an abnormal location.1,2

Brain heterotopias are generally considered congenital malformations embryologically related to encephalocele from which they are differentiated by absence of anatomic connection with the brain. ${ }^{3}$

Most common site for brain heteropia is nasal cavity but can occur in other sites less commonly in the pharynx, tongue, palate, orbit.-6 In the tongue cartilaginous and osseous choristoma are reported more commonly in the older age group. 7,8

Other Choristoma that can occur in oral cavity include. ${ }^{9}$

1. Salivary gland choristoma

2. Cartilaginous Choristoma.

3. Oral Osseous Choristoma

4. Lingual Thyroid Choristoma.

5. Lingual Sebaceous Choristoma.

6. Glial choristoma

7. Gastric and respiratory mucosa.

In newborn nasal gliomas are commonly reported and the involvement of tongue for glial choristoma is rare. Gastric choristoma is frequently seen in small intestine, gall bladder, biliary tract, meckels diverticulum, colon and rectum. ${ }^{10}$

Majority are products of uncomplicated pregnancies. There seems to be a female predominance with no syndromic predisposition. ${ }^{4}$ No known etiological factors have so far been identified. Patients may have other craniofacial anomalies such as cleft palate, choanal atresia, micrognathia; macrostomia. ${ }^{11}$ Our case had an associated cleft palate. CT and MRI are complementary studies that are necessary in preoperative planning to determine the extent and location of the mass and to exclude intracranial connection. Surgical excision is the treatment of choice. 


\section{CASE REPORT}

CASE REPORT: A term female neonate, weighing $2.5 \mathrm{~kg}$ presented to our unit at four hours of life with mild respiratory distress and mass arising from oral cavity. Neonate was born of normal spontaneous vaginal delivery, a product of consanguineous marriage, with maternal polyhydramnios and a prenatal ultrasound at 23 weeks gestation showing fronto ethmoidal encephalocele.

A targeted imaging for fetal anomalies at 27 weeks gestation reported cystic hygroma. The physical examination revealed a pedunculated, pink mass with well-defined borders arising from the left lateral border of tongue from anterior two-thirds, measuring $8 \times 6 \times 4 \mathrm{~cm}$ extending up to level of left clavicle. Cleft palate was also detected on examination (Fig. 1).

The neonate underwent surgery at fifth day of life under general anesthesia and the mass was completely excised with a trans oral approach and the tissue was sent for histopathology. Gross picture showed grey white brown globular mass measuring tissue $8 \times 6 \times 4 \mathrm{~cm}$ with external surface hemorrhages. Cut section: solid and cystic areas with yellow color borders.

The microscopic examination revealed mature brain tissue showing hyper cellular areas with cystic spaces containing papillary projections of cuboidal cells morphologically identical to choroid plexus. No immature or teratomatous component could be identified and thus diagnosed as choristoma of tongue (Fig. 2).

The post-operative period was uneventful until $20^{\text {th }}$ day of life. Then the neonate presented with a swelling measuring $4 \times 5 \mathrm{~cm}$ in the left submandibular area extending up to the left supra clavicular region. MRI of neck and soft tissue revealed large mixed intense areas with T2 hyper intense areas in the left side of oral cavity and left sub mandibular region displacing muscles of tongue superiorly and to right side compromising posterior part of oral cavity and oro pharynx with no intra cranial or intra thoracic connection and a defect in the posterior part of hard palate was noted (Fig. 3).

Mass was removed by a second surgery and specimen was sent for histopathology. Histology report of the second mass from neck measuring $4 \times 4 \times 3 \mathrm{~cm}$ with cut section showing grey white solid to cystic areas and microscopy revealed heterogeneous tissue consisting of aggregates of mucin and serous secreting salivary glands, intestinal epithelium with all circular and longitudinal muscle with serosa and pancreatic tissue. No evidence of immature tissue seen thus diagnosed as heterotopia of intestine.

The neonate was discharged on oral feeds at one and half month of age. At three month of follow up infant is normal with no complications and recurrence of mass.

DISCUSSION: Choristomas are usually asymptomatic. In oral cavity approximately $30 \%$ can show increased salivation, altered speech, difficulty in swallowing, feeding and respiration ${ }^{12}$. Choristoma of larynx and hypopharynx present with airway obstruction and dysphagia ${ }^{13}$.The differential diagnosis of masses in oral cavity include teratoma, glioma, hemangioma, cystic hygroma, heterotopic brain tissue, neuro fibroma, myofibroma, encephalocele. ${ }^{12,13}$ If the tissue specimen contains mature neural tissue the differential diagnosis is limited to three entities: teratoma, encephalocele and heterotopic neural tissue.

Differentiation of these tumors can be made according to clinic, pathological and radiographic correlation. CT and MRI are complementary studies that are necessary in pre-operative planning to determine the extent and location of the mass and to exclude intra cranial connection. 
Brain heterotopias are composed of nests of neural tissue without mitosis embedded within varying amount of fibro vascular stroma. Neurons are detected in ten percent of cases. Oro pharyngeal glial choristoma mainly contains neurons and astrocytes as well as complex central nervous system elements, such as ependymal line structures - choroid plexus. Heterotropic neural glial tissue composed of only ectodermal elements which distinguishes it from teratoma which is composed of all three germ layers.

Heterotopic gastric mucosa may present as both solid and cystic forms. Cystic variant is often referred to as heterotopic oral gastro-intestinal cyst leading to confusion with foregut duplication cyst whereas solid variant has been called gastric heterotopia ${ }^{13}$. Solid variant is commonly seen in upper aero digestive tract from naso pharynx to oro pharynx. Several hypotheses to explain development of glial choristoma exist.

Nest of pleuripotential cells that have become separated before the complete fusion of neural tube, integrates with myoblast, and migrates to tongue ${ }^{14}$.Histogenesis of gastro-intestinal heterotopia is derived from misplaced embryonal remnants during fetal development. Khunamornpong $\mathrm{S}$ et al in 1996 reported a case of cleft palate with tongue mass containing gastro-intestinal mucosa and pancreas in an eight month old infant.

Erdal Endreum et al in 2001reported gastric choristoma of tongue with prognathic mandible and cleft palate. Tumor resection in neonatal period allows early oral feeding and normal development of swallowing and pharyngeal coordination. Resection should be as complete as possible with no damage to vital structures or compromising the functions.

CONCLUSION: Mixed glial heteropia of tongue from anterior two third and lateral border measuring $8 \times 6 \times 4 \mathrm{~cm}$ and gastro intestinal choristoma of oral cavity with pancreatic tissue is a very rare presentation in female, term newborn, with associated cleft palate. Early complete surgical excision provides curative treatment without recurrence.

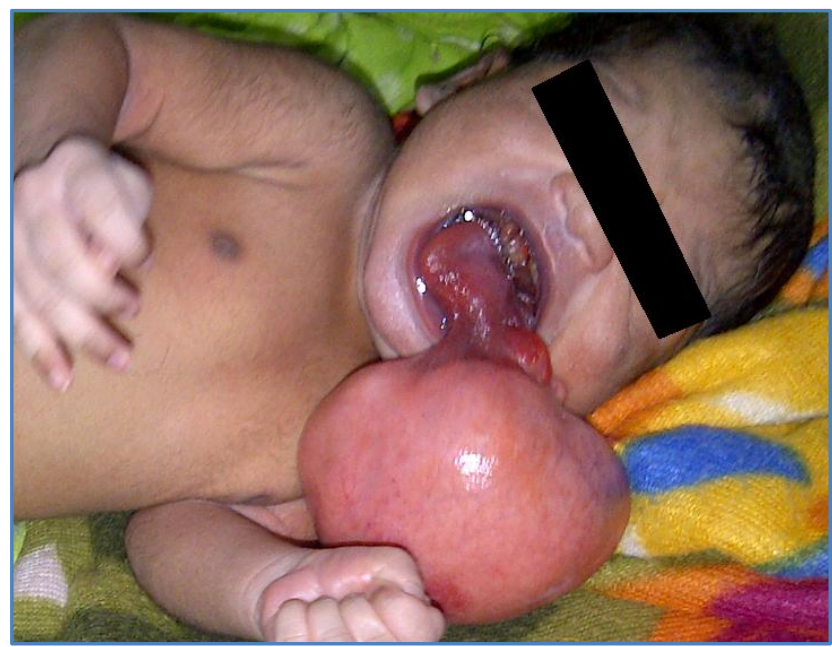

Figure 1: Clinical picture showing mass arising from tongue 


\section{CASE REPORT}

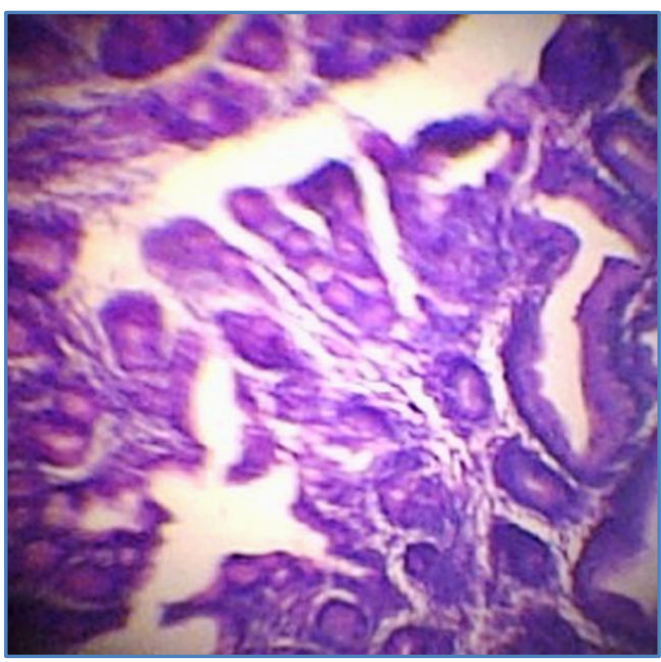

Figure 2: microscopic picture of the first mass

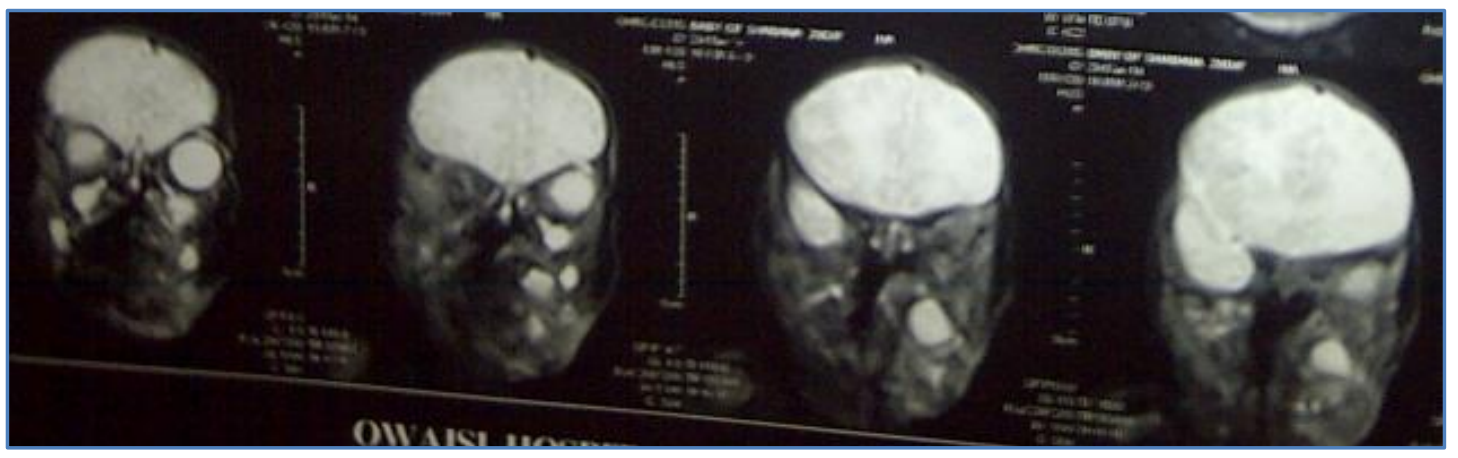

Figure 3: MRI of soft tissue swelling

\section{REFERENCES:}

1. Buckmiller LM, Brodie HA, Doyle KJ, Nemzek W. Choristoma of the middle ear: A component of a new syndrome. Otol Neurotol 2001; 22: 363-8.

2. Jong Im Lee, Ki Kwon Kim, Yoon Keun Park, Kyung Yoon Eah, and Jung Ran Kim. J Korean Med Sci. Feb 2004; 19(1): 155-158.

3. M.D. García-Prats, J.L. Rodríguez-Peralto, R. Carrillo. Glial choristoma of the tongue: Report of a Case J Oral Maxillofac Surg. 1994; 52: 977-980

4. Broniatowski M, Witt WJ, Shah AC, Galloway PG, Abramowsky CR. Glial tissue in the parapharyngeal space. Arch Otolaryngol. 1981; 107: 636 - 641.

5. Knox R, Pratt M, Garvin AJ, White B. Heterotopic lingual brain in the newborn. Arch Otolaryngol Head Neck Surg. 1989; 115: 630 - 632.

6. Pryce DW, Khine M, Verbov JL, van Velzen D. Scalp cyst with heterotopic brain tissue. Br J Dermatol. 1993; 129: 183 - 185.

7. Krolls SO, Jacoway JR, Alexander WN. Osseous Choristomas (Osteomas) of intra oral soft tissues. Oral Surg 1971; 32:588-595. 
8. Supiyaphun P, Sampatanakul P, Kerekhanjanarong V, Aeumjaturapat S, Sastarasadhit V. Lingual osseous choristoma: report of three cases. J Med Assoc Thai 2000; 83(5):564-8.

9. Chou L, Hansen LS, Daniels TE. Choristoma of the oral cavity: A review. Oral Surg Oral Med Oral Pathol 1991; 72:584-593.

10. Picard EJ, Picard JJ, Jorissen J, Jardon M. Heterotropic gastric mucosa in the epiglottis and rectum. Am J Dig Dis 1978; 23:217-21.

11. Madjidi A, Couly G. Heterotopic neuroglial tissue of the face. Report of six cases and review of the literature. Oral Surg Oral Med Oral Path 1993; 76:284 -8

12. Fan SQ, Ou YM, Liang QC. Glial choristoma of the tongue: Report of a case and review of the literature. Pediatr Surg Int 2008; 24:515-9.

13. Desuter G, Plouin-Gaudon I, de Toeuf C, Gosseye S, Hamoir M. Gastric choristoma of the midline neck in a newborn: A case report and review of the literature. J Pediatr Surg 2003; 38:E1-3.

14. Mohanty S, Das K, Correa MA, Cruz AJ. Extranasal glial heterotopia: Case report. Neurol India 2003; 51:248-9

15. Gorlin RJ, Jirasek JE. Oral cysts containing gastric or intestinal mucosa: An unusual embryological accident or heterotopia. Arch Otolaryngol 1970; 91:594-7

\section{AUTHORS:}

1. S. Pratap Rao

2. B. Jyothsna

3. Sana Salim Khan

4. M. Sravanthi

5. C. N. Prasad

\section{PARTICULARS OF CONTRIBUTORS:}

1. Professor, Department of Paediatrics, Deccan College of Medical Sciences, Hyderabad, Andhra Pradesh, India.

2. Assistant Professor, Department of Paediatrics, Deccan College of Medical Sciences, Hyderabad, Andhra Pradesh, India.

3. Resident, Department of Paediatrics, Deccan College of Medical Sciences, Hyderabad, Andhra Pradesh, India.

4. Resident, Department of Paediatrics, Deccan College of Medical Sciences, Hyderabad, Andhra Pradesh, India.
5. Professor, Department of Paediatric Surgery, Deccan College of Medical Sciences, Hyderabad, Andhra Pradesh, India.

\section{NAME ADDRESS EMAIL ID OF THE CORRESPONDING AUTHOR:}

Dr. B. Jyothsna, \#17-1-388/5,

Laxmi Nagar Colony,

Saidabad.

Email: pjyoths@yahoo.com

Date of Submission: 10/05/2014.

Date of Peer Review: 11/05/2014.

Date of Acceptance: 17/05/2014.

Date of Publishing: 24/05/2014. 